\title{
Advances for the pharmacotherapy of depression - Presenting the rising star: $\mathrm{Ca}^{2+} / \mathrm{camp}$ signaling interaction
}

\author{
Leandro Bueno Bergantin ${ }^{1 *}$ and Afonso Caricati-Neto ${ }^{1}$ \\ ${ }^{1}$ Department of Pharmacology - Universidade Federal de São Paulo - Escola Paulista de Medicina, Laboratory of Autonomic and Cardiovascular Pharmacology - \\ 5511 5576-4973, Rua Pedro de Toledo, 669 - Vila Clementino, São Paulo - SP, Brazil
}

\begin{abstract}
The pharmacotherapy for treating depression is clearly limited. The classical pharmacotherapy that exists nowadays was developed decades ago. Indeed, depression is characterized by reduction of neurotransmitters release in central nervous system, mainly serotonin and catecholamines. Besides, since 70's several clinical studies have reported that administration of $\mathrm{Ca}^{2+}$ channel blockers (CCBs) produces reduction in vascular resistance associated with an increase in sympathetic hyperactivity, originated from increase of neurotransmitter release. In 2010 's, we discovered that this paradoxical sympathetic hyperactivity produced by CCBs is mediated by $\mathrm{Ca}^{2+} / \mathrm{cAMP}$ signalling interaction ( $\mathrm{Ca}^{2+} / \mathrm{cAMP}$ interaction) acting by increasing neurotransmitter release. Considering this interaction has been postulated to be universally-operated in neuroendocrine cells, the pharmacological handling of the $\mathrm{Ca}^{2+} / \mathrm{cAMP}$ interaction is a clear rising star for increasing neurotransmitter release, including serotoninergic and monoaminergic neurotransmission in depression. This mini review compiles our previous results published in 7 cited international papers, herein discussing novel strategies to treat depression, throughout our discovery entitled "calcium paradox" phenomenon due to interaction of $\mathrm{Ca}^{2+} / \mathrm{cAMP}$ intracellular signalling pathways.
\end{abstract}

\section{Introduction}

The treatment of depression by current pharmacotherapy is clearly restricted. The classical pharmacotherapy that exists in the present was developed decades ago. Depression is a psychiatric disease resulting mainly by dysfunction of monoaminergic neurotransmission in central nervous system [1,2]. Depression is a severe global illness, becoming more and more common each decade. Because of specific symptoms, it is considered as a leading cause of disability all over the world with a high death factor due to suicides. There are many antidepressants used in the pharmacotherapy, but still more than one-third of patients do not respond to the current therapy [2]. In addition to the monoaminergic hypothesis of depression, there are also many other approaches connected with the pathophysiology of this disease, including hypothalamic-pituitary-adrenal axis dysregulation, dopaminergic, cholinergic, glutamatergic or GABAergic neurotransmission [2]. Complementing these hypotheses, the neurotrophic one is also emerging. The preclinical and clinical data, and imaging studies, support a neurotrophic hypothesis of depression, and antidepressant responses [3,4]. This hypothesis proposes that depression results from decreased neurotrophic support, leading to neuronal atrophy, decreased hippocampal neurogenesis and loss of glia. It is proposed that antidepressant treatment blocks, or reverses, this neurotrophic factor deficit, and thereby reverses the atrophy and cell loss [3,4]. Nevertheless, it can be unambiguously stated that serotonergic, noradrenergic and dopaminergic systems (monoaminergic neurotransmission) are clearly associated with pathogenesis of depression, and are therefore considered as valuable targets in patients' treatment. In this mini review, we discuss novel strategies to treat depression, throughout our recent discovery entitled "calcium paradox" phenomenon due to interaction of $\mathrm{Ca}^{2+} / \mathrm{cAMP}$ intracellular signalling pathways [1,5-10].

\section{Current hypothesis for depression and its pharmaco- therapy}

Depression is a debilitating psychiatric condition that causes a significant problem on human health. There is still a deficiency of a clear comprehension of the neuropathological changes associated with this illness, and the efficacy of antidepressants is very limited [11]. Research into antidepressant therapies has derived from observations in human trials and animal models after the first monoaminergic hypothesis emerged decades ago. In addition, glutamatergic modulators, such as ketamine also have become the forefront of antidepressant exploration, especially for treatment-resistant depression and suicidal ideation [11]. The glutamatergic hypothesis of depression is not novel, however other NMDA receptor modulators do not seem to share the rapid and sustained effects of ketamine, suggesting that a unique combination of intracellular targets might be involved in its effect $[11,12]$. Nonetheless, the monoamine hypothesis of depression continues to lead the field and clinical trials, which postulates that an imbalance in monoaminergic neurotransmission is causally related to the clinical features of depression [12]. Antidepressants influence serotonin whose mainly goal consist at raising serotonin concentrations, thereby increasing serotonergic transmission at the level of the synapse, for example by inhibiting the serotonin transporter. However, the serotonin system is multifaceted. Different serotonin receptor subtypes turn the serotonergic system into a complex neurochemical arrangement that

Correspondence to: Department of Pharmacology - Universidade Federal de São Paulo - Escola Paulista de Medicina, Laboratory of Autonomic and Cardiovascular Pharmacology - 5511 5576-4973, Rua Pedro de Toledo, 669 Vila Clementino, São Paulo - SP, Brazil, CEP: 04039-032, E-mail: leanbio39@ yahoo.com.br

Received: January 20, 2017; Accepted: April 24, 2017; Published: April 27, 2017 
influences diverse neurotransmitters in various brain regions. Classical antidepressants, as well as other psychopharmacological agents have various crucial effects on serotonin receptors. Researchers aim to provide a useful characterization of serotonin receptor subtypes in the treatment of depression. Clarifying the mode of action and the interplay of serotonin receptors with pharmacological agents should help elucidate antidepressant mechanisms and typical side effects to better understanding. In addition, clinical medicine featured the novel antidepressants vortioxetine, vilazodone and milnacipran/ levomilnacipran with regard to their serotonin receptor targets such as the 5-HT1A, 5-HT3 and 5-HT7, which may account for their specific effects on certain symptoms of depression as well as a characteristic side-effect profile [12].

The combination of novel ideas added to improvements on the discoveries may lead to advances in antidepressant research field with the promise of finding pharmaceuticals more effective. Thus, new visions for more efficient pharmacological treatments of depression are clearly needed.

\section{Presenting the rising star: $\mathrm{Ca}^{2+} / \mathrm{cAMP}$ signalling inter- action}

Although the cellular and molecular mechanisms involved in the synergistic actions of cAMP on the exocytosis of neurotransmitter and hormones remain under debate, the evidences suggest that this intracellular messenger can participate in the regulation of exocytosis due to its modulatory action on the intracellular $\mathrm{Ca}^{2+}$ signals. Indeed, this concept was initially resulted from the study of cat adrenal gland perfused with acetylcholine executed by Douglas and Rubin in the 1960s [13]. The discovery that increase in the cytosolic $\mathrm{Ca}^{2+}$ concentration $\left(\left[\mathrm{Ca}^{2+}\right]\right.$ c) was a basic requirement for exocytosis in adrenal catecholaminergic cells was made by Baker and Knight in 1970's [14]. In addition, some studies showed that cAMP rises transmitter release at many synapses in autonomic nervous system of vertebrate, including sympathetic and parasympathetic ganglion neurons [15]. The hypothesis for an interaction between the intracellular signalling pathways mediated by $\mathrm{Ca}^{2+}$ and $\mathrm{cAMP}\left(\mathrm{Ca}^{2+} / \mathrm{cAMP}\right.$ interaction $)$ has been extensively studied in many cells and tissues. Generally, this interaction results in synergistic effects on cell functions $[1,5,6,16,17]$ and occurs at the level of adenylyl cyclases (ACs) or phosphodiesterases (PDEs) (Figure 1). The $\mathrm{Ca}^{2+} /$ cAMP interaction has particularly been extensively studied at the $\mathrm{Ca}^{2+}$ channels [e.g.: ryanodine receptors (RyR)] of the endoplasmic reticulum (ER) $[1,5,6,16,17]$. Phosphorylation of RyR by protein kinase A (PKA), and also inositol trisphosphate receptor $\left(\mathrm{IP}_{3} \mathrm{R}\right)$ at submaximal $\mathrm{IP}_{3}$ concentrations, may increase the open probability of $\mathrm{ER} \mathrm{Ca}^{2+}$ stores, amplifying $\mathrm{Ca}^{2+}$-induced $\mathrm{Ca}^{2+}$ release (CICR) mechanism and cellular responses [1,5,6] (Figure 1). Recent evidences suggest that $\mathrm{Ca}^{2+} /$ cAMP interaction participates in exocytosis regulation of neurons and neuroendocrine cells $[1,5,6]$. Then, dysfunctions of cellular homeostasis of $\mathrm{Ca}^{2+}$ and/or cAMP in these cells could result in the dysregulation of $\mathrm{Ca}^{2+} / \mathrm{cAMP}$ interaction and exocytotic response, or could be a novel therapeutic target for medicines (Figure 1).

Since 1975, nifedipine and verapamil, classical L-type $\mathrm{Ca}^{2+}$ channel blockers (CCBs) have been reported to produce reduction in peripheral vascular resistance and arterial pressure associated with an increase in plasma noradrenaline levels and heart rate, typical signals of sympathetic hyperactivity [18]. However, the cellular and molecular mechanisms involved in this apparent sympathomimetic effect of the L-type CCBs remained unclear for decades. In addition, experimental studies using isolated tissues richly innervated by sympathetic nerves showed that neurogenic responses were completely inhibited by L-type CCBs in high concentrations $(>1 \mu \mathrm{mol} / \mathrm{L})$, but paradoxically potentiated in concentrations below $1 \mu \mathrm{mol} / \mathrm{L}$ [19-21]. During almost four decades, these enigmatic phenomena named by us as "calcium paradox" remained unclear. In 2013, we discovered that this paradoxical increase in sympathetic activity produced by L-type CCBs is due to $\mathrm{Ca}^{2+} / \mathrm{cAMP}$ interaction [5]. Then, the pharmacological manipulation of the $\mathrm{Ca}^{2+} /$ cAMP interaction produced by combination of the L-type CCBs used in the antihypertensive therapy, and cAMP accumulating compounds used in the anti-depressive therapy such as rolipram, could represent a potential cardiovascular risk for hypertensive patients due to increase in sympathetic hyperactivity. In contrast, this pharmacological manipulation could be a new therapeutic strategy for increasing neurotransmission in the psychiatric disorders, such as depression.

In addition, several studies have been demonstrating pleiotropic effects of CCBs. CCBs, like nifedipine, genuinely potentiate the effect of tricyclic and atypical antidepressants $[22,23]$. However, the molecular mechanisms involved in these pleiotropic effects remain under debate. In fact, apart from its classical functions, CCBs are described to have beneficiary roles on the cognitive profile of the aged population and individuals with hypertension, diabetes, Parkinson's disease, and Alzheimer's disease [24-27]. Different mechanisms have been proposed, but the exact mechanisms of antidepressant effects and cognitive improvement are still uncertain. Then, the pharmacological implications of the $\mathrm{Ca}^{2+} / \mathrm{cAMP}$ interaction produced by this drug combination could be used to enhance neurotransmission [1,5-10].

Recent studies have shown that chronic treatment with rolipram, together with typical antidepressants has been successful in the reduction of depression symptoms due to potentiation of these antidepressants effects [28-30]. Considering our model in which increment of $[\mathrm{cAMP}] \mathrm{c}$ stimulates $\mathrm{Ca}^{2+}$ release from ER (Figure 1), it may be plausible that the therapeutic use of the PDE inhibitor rolipram $[28,29]$, in combination with low doses of verapamil to potentiate neurotransmission (Figure 1) in the areas of central nervous system involved in neurological/psychiatric disorders in which neurotransmission is reduced, including depression. This new pharmacological strategy for the treatment of psychiatric disorders could increase the therapeutic efficacy and reduce the adverse effects of the medicines currently used for treating depression. Considering that CCBs genuinely exhibit cognitive-enhancing abilities and reduce the risk of psychiatric disorders like depression, and that the mechanisms involved in these pleiotropic effects are largely unknown. For example: it was demonstrated that the administration of L-type CCBs reduces motor symptoms and progressive neuronal death in animal model of Parkinson's disease, indicating that L-type CCBs are potentially viable neuroprotective pharmaceuticals [31]. Intriguingly, a 1-decade study involving thousands senile hypertensive patients demonstrated that prescription of L-type CCBs reduced blood pressure, and risk of dementia in hypertensive patients, indicating that these pharmaceuticals could be clinically used to treat neurodegenerative diseases [32]. These results for the neuroprotective effects of CCBs have been reinvestigated in thousands elderly hypertensive patients with memory dysfunction [33]. These studies concluded that patients who have taken CCBs had their risk of cognitive dysfunction decreased, such as Alzheimer's disease [33]. These findings reinforce the idea that reduction of cytosolic $\mathrm{Ca}^{2+}$ overload produced by L-type CCBs due to blockade of $\mathrm{Ca}^{2+}$ influx could be an alternative pharmacological goal to reduce, or prevent, neuronal death in neurodegenerative diseases. Then, whether $\mathrm{Ca}^{2+} / \mathrm{cAMP}$ interaction is involved in such effects deserves special attention. 


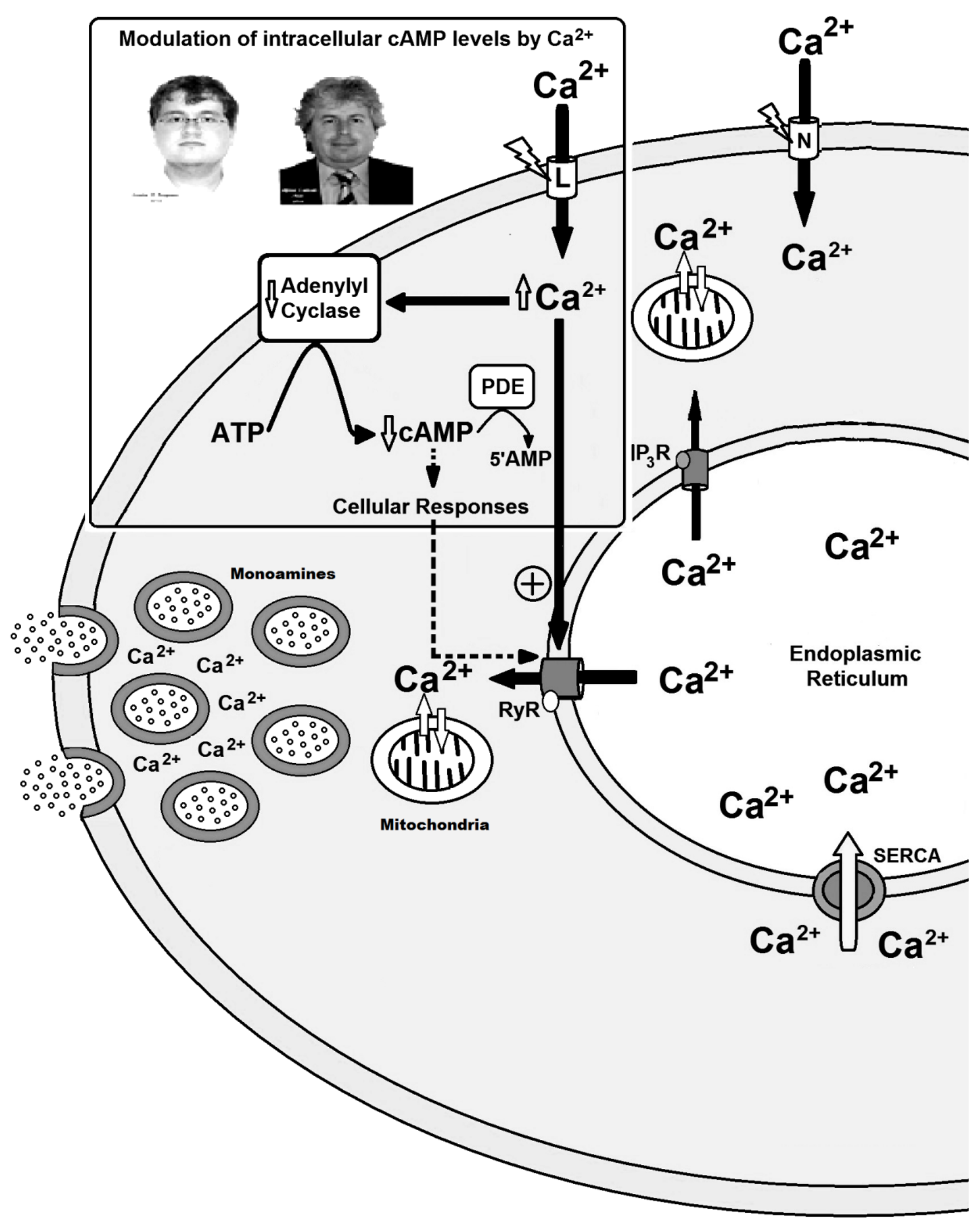

Figure 1. Example of a monoaminergic cell. Role of $\mathrm{Ca}^{2+/} \mathrm{cAMP}$ interaction in neurotransmitter release, including monoamines from central system nervous. Cellular homeostasis of $\mathrm{Ca}^{2+}$ and/or cAMP in these cells could result in the dysregulation of $\mathrm{Ca}^{2+} / \mathrm{cAMP}$ interaction and exocytotic response of monoamines, or could be a novel therapeutic target for medicines, according to our previous studies [1,5-10]. 
In addition, considering $\left[\mathrm{Ca}^{2+}\right] \mathrm{c}$ elevation could contribute to both: negatively to neuroprotective effects and positively to exocytosis, it may be plausible the therapeutic use of the PDEs inhibitors [28-30] for antidepressant purposes. Then, pharmacological interference of the $\mathrm{Ca}^{2+} /$ cAMP interaction produced by combination of L-type CCBs and cAMP-accumulating compounds could enhance antidepressant response and reduce clinical symptoms of psychiatric disorders. Thus, the association of currently medicines could enhance antidepressant treatments. For example: the association of typical antidepressants with CCBs or rolipram could dramatically improve typical antidepressant medicines, mainly by reducing their adverse effects and increasing their effectiveness. This new pharmacological strategy could be alternatively used for treatment of the symptoms of psychiatric disorders, including depression [1,5-10,28-30].

\section{Conclusion}

In conclusion, this mini review compiles our previous results [1,510], herein discussing novel strategies to treat depression, throughout our discovery entitled "calcium paradox" phenomenon due to interaction of $\mathrm{Ca}^{2+} / \mathrm{cAMP}$ intracellular signalling pathways. Although pharmacological therapies have been largely unsuccessful in curing depression, targeting potential risk factors aiming to decrease incidence of this psychiatric disorder is an important public health edge. Finally, novel strategies to treat depression, throughout our recent discovery entitled "calcium paradox" phenomenon due to interaction of $\mathrm{Ca}^{2+} /$ cAMP intracellular signalling pathways, could greatly contribute to enhance therapeutic strategies for increasing neurotransmission. Thus, the association of typical antidepressants with CCBs or rolipram could dramatically improve antidepressant therapies, mainly by reducing adverse effects and improving effectiveness of these typical antidepressants.

\section{Disclosure statement}

Caricati-Neto and Bergantin thank the continued financial support from CAPES, CNPq and FAPESP (Bergantin's Postdoctoral Fellowship FAPESP \#2014/10274-3).

\section{References}

1. Caricati-Neto A, García AG, Bergantin LB (2015) Pharmacological implications of the $\mathrm{Ca}^{2+/} \mathrm{cAMP}$ signalling interaction: from risk for antihypertensive therapy to potential beneficial for neurological and psychiatric disorders. Pharmacol Res Perspect 3: e00181. [Crossref]

2. Pytka K, Podkowa K, Rapacz A, Podkowa A, Å»mudzka E, et al. (2016) The role of serotonergic, adrenergic and dopaminergic receptors in antidepressant-like effect. Pharmacol Rep 68: 263-274. [Crossref]

3. Duman RS, Monteggia LM (2006) A neurotrophic model for stress-related mood disorders. Biol Psychiatry 59: 1116-1127. [Crossref]

4. Duman RS, Heninger GR, Nestler EJ (1997) A molecular and cellular theory of depression. Arch Gen Psychiatry 54: 597-606. [Crossref]

5. Bergantin LB, Souza CF, Ferreira RM, Smaili SS, Jurkiewicz NH, et al. (2013) Novel model for "calcium paradox" in sympathetic transmission of smooth muscles: role of cyclic AMP pathway. Cell Calcium 54: 202-212. [Crossref]

6. Bergantin LB, Jurkiewicz A, García AG, Caricati-Neto A (2015) A Calcium Paradox in the Context of Neurotransmission. Journal of Pharmacy and Pharmacology 3: 253261. [Crossref]

7. Bergantin LB, Caricati-Neto A (2016) Insight from "Calcium Paradox" due to $\mathrm{Ca}^{2+}$ cAMP Interaction: Novel Pharmacological Strategies for the Treatment of Depression. Int Arch Clin Pharmacol 2: 007. [Crossref]

8. Bergantin LB, Caricati-Neto A (2016) Novel Insights for Therapy of Parkinson's disease: Pharmacological Modulation of the $\mathrm{Ca}^{2+} / \mathrm{cAMP}$ Signalling Interaction. Austin Neurol \& Neurosci: 1009. [Crossref]
9. Bergantin LB, Caricati-Neto A (2016) Challenges for the pharmacological treatment of neurological and psychiatric disorders: Implications of the $\mathrm{Ca}^{2+} / \mathrm{cAMP}$ intracellular signalling interaction. European Journal Pharmacology 788: 255-260. [Crossref]

10. Bergantin LB, Caricati-Neto A (2016) Recent advances in pharmacotherapy of neurological and psychiatric disorders promoted by discovery of the role of $\mathrm{Ca}^{2+}$ cAMP signaling interaction in the neurotransmission and neuroprotection. Advance Pharmaceutical Journal 1: 66-70.

11. Kaster MP, Moretti M, Cunha MP, Rodrigues AL (2016) Novel approaches for the management of depressive disorders. Eur J Pharmacol 771: 236-240. [Crossref]

12. Köhler S, Cierpinsky K, Kronenberg G, Adli M (2016) The serotonergic system in the neurobiology of depression: Relevance for novel antidepressants. $J$ Psychopharmacol 30: 13-22. [Crossref]

13. DOUGLAS WW, RUBIN RP (1961) The role of calcium in the secretory response of the adrenal medulla to acetylcholine. J Physiol 159: 40-57. [Crossref]

14. Baker PF, Knight DE (1978) Calcium-dependent exocytosis in bovine adrenal medullary cells with leaky plasma membranes. Nature 276: 620-622. [Crossref]

15. Chern YJ, Kim KT, Slakey LL, Westhead EW (1988) Adenosine receptors activate adenylate cyclase and enhance secretion from bovine adrenal chromaffin cells in the presence of forskolin. J Neurochem 50: 1484-1493. [Crossref]

16. Cooper DM, Mons N, Karpen JW (1995) Adenylyl cyclases and the interaction between calcium and cAMP signalling. Nature 374: 421-424. [Crossref]

17. Yule DI, Betzenhauser MJ, Joseph SK (2010) Linking structure to function: recent lessons from inositol 1,4,5-trisphosphate receptor mutagenesis. Cell Calcium 47: 469479. [Crossref]

18. Grossman E, Messerli FH (1998) Effect of calcium antagonists on sympathetic activity. Eur Heart J 19 Suppl F: F27-31. [Crossref]

19. Kreye VA, Lüth JB (1975) Proceedings: Verapamil-induced phasic contractions of the isolated rat vas deferens. Naunyn Schmiedebergs Arch Pharmacol 287 Suppl: R43. [Crossref]

20. French AM, Scott NC (1981) A comparison of the effects of nifedipine and verapamil on rat vas deferens. Br J Pharmacol 73: 321-323. [Crossref]

21. Moritoki H, Iwamoto T, Kanaya J, Maeshiba Y, Ishida Y, et al. (1987) Verapami enhances the non-adrenergic twitch response of rat vas deferens. Eur J Pharmacol 140: 75-83. [Crossref]

22. Prakhie IV, Oxenkrug GF (1998) The effect of nifedipine, Ca(2+) antagonist, on activity of MAO inhibitors, $\mathrm{N}$-acetylserotonin and melatonin in the mouse tail suspension test. Int J Neuropsychopharmacol 1: 35-40. [Crossref]

23. De Vry J, Fritze J, Post R (1997) The management of coexisting depression in patients with dementia: potential of calcium channel antagonists. Clinical Neuropharmacology 20: 22-35. [Crossref]

24. Ogihara T, Nakagawa M, Ishikawa H, Mikami H, Takeda K, et al. (1992) Effect of manidipine, a novel calcium channel blocker, on quality of life in hypertensive patients. Blood Press Suppl 3: 135-139. [Crossref]

25. Veng LM, Mesches MH, Browning MD (2003) Age-related working memory impairment is correlated with increases in the L-type calcium channel protein alpha1D (Cav1.3) in area CA1 of the hippocampus and both are ameliorated by chronic nimodipine treatment. Brain Res Mol Brain Res 110: 193-202. [Crossref]

26. Chan CS, Guzman JN, Ilijic E, Mercer JN, Rick C, et al. (2007) 'Rejuvenation' protects neurons in mouse models of Parkinson's disease. Nature 447: 1081-1086. [Crossref]

27. Tsukuda K, Mogi M, Li JM, Iwanami J, Min LJ, et al. (2008) Diabetes-associated cognitive impairment is improved by a calcium channel blocker, nifedipine. Hypertension 51: 528-533. [Crossref]

28. Sommer N, Loschmann PA, Northoff GH, Weller M, Steinbrecher A, et al. (1995) The antidepressant rolipram suppresses cytokine production and prevents autoimmune encephalomyelitis. Nat Med 1: 244-248. [Crossref]

29. Li YF, Cheng YF, Huang Y, Conti M, Wilson SP, et al. (2011) Phosphodiesterase-4D knock-out and RNA interference-mediated knock-down enhance memory and increase hippocampal neurogenesis via increased cAMP signaling. J Neurosci 3: 172-183. [Crossref]

30. Xiao L, O'Callaghan JP, O'Donnell JM (2011) Effects of repeated treatment with phosphodiesterase-4 inhibitors on cAMP signaling, hippocampal cell proliferation, and behavior in the forced-swim test. J Pharmacol Exp Ther 338: 641-647. [Crossref]

31. Ilijic E, Guzman JN, Surmeier DJ (2011) The L-type channel antagonist isradipine is neuroprotective in a mouse model of Parkinson's disease. Neurobiol Dis 43: 364-371. [Crossref] 
Bergantin LB (2017) Advances for the pharmacotherapy of depression - Presenting the rising star: $\mathrm{Ca}^{2+} / \mathrm{camp}^{2}$ signaling interaction

32. Wu CL, Wen SH (2016) A 10-year follow-up study of the association between calcium channel blocker use and the risk of dementia in elderly hypertensive patients. Medicine 95: e4593. [Crossref]
33. Hanon O, Pequignot R, Seux ML, Lenoir H. et al. (2006) Relationship between antihypertensive drug therapy and cognitive function in elderly hypertensive patients with memory complaints. J Hypertens 24: 2101-2107. [Crossref]

Copyright: (C2017 Bergantin LB. This is an open-access article distributed under the terms of the Creative Commons Attribution License, which permits unrestricted use, distribution, and reproduction in any medium, provided the original author and source are credited. 